\section{G206(P) UNDERGRADUATE PERCEPTIONS OF PAEDIATRIC SIMULATION}

'P Darkin, ${ }^{2} \mathrm{M}$ Hodin. Childrens Services, St George's University Hospitals NHS Trust, London, UK

\subsection{6/archdischild-2020-rcpch. 174}

Aims To evaluate a newly developed undergraduate paediatric simulation curriculum, specifically identifying student-perceived benefits and challenges of the learning experience. Few studies to date have explored student perceptions.

Methods Since September 2018, after an initial pilot study, penultimate year medical students have taken part in a novel paediatric simulation programme as part of their curriculum. The timetable consists of four sessions each focusing on a single paediatric emergency. Feedback questionnaires were completed after each session. The pilot study showed a significant increase in confidence about managing future paediatric emergencies. This study focused on evaluation of attitudes towards learning from simulation at undergraduate level.

Results 70 responses were collected and thematically analysed to interpret barriers and enablers to learning. The full hierarchical coding tree will be given at presentation.

'What did you find useful' themes related to gaining new or revising existing theoretical knowledge (by far the commonest theme) and learning new practical skills. Non-clinical themes also arose, including adopting a systematic approach, developing communication skills and improving teamwork.

'What did you find challenging' themes echoed this, with learning new technical skills being the most common. Similarly, paucity of existing knowledge and difficulty acquiring a new skill were also common themes. Challenges relating to non-clinical skills were less frequently described but included keeping calm, decision making and prioritisation. Development of communication skills and teamwork strategies were only perceived as a challenge for a minority of students.

Conclusion Research has shown that post-graduate simulationbased learning is weighted towards non-clinical themes. Our thematic analysis suggests that at undergraduate level perceptions are different; although non-clinical themes emerge, clinical themes are much more prevalent.

Faculty were surprised by and reflected upon these findings, exploring why this might be. We hypothesise that paucity of prior clinical knowledge can be a barrier to learning effectively in this environment at this educational level.

Responding to our learners' needs we plan to introduce a knowledge-based session prior to the programme, with associated supportive learning resources, and a session introducing the wider learning opportunities within simulation, with the aim of mitigating barriers to non-clinical learning.

\section{G207(P) SIMULATION IN COMMUNITY PAEDIATRICS FOR $5^{\text {TH }}$ YEAR MEDICAL STUDENTS: CAN IT WORK?}

K Ferin, I Shein, P Julies. Community Child Health, Royal Free NHS FT, London, UK

\subsection{6/archdischild-2020-rcpch. 175}

Objectives To assess whether simulation is an effective method for teaching community paediatric topics to 5 th year medical students.

Background The community paediatrics programme for 5th year medical students at UCL consists of:

\begin{tabular}{|c|c|c|}
\hline Teaching Method & Challenges & Feedback \\
\hline \multicolumn{3}{|l|}{ Previous: } \\
\hline $\begin{array}{l}\text { Practicing developmental } \\
\text { assessment on typically } \\
\text { developing children }\end{array}$ & $\begin{array}{l}\text { Regular recruitment of sufficient } \\
\text { numbers and ages of children }\end{array}$ & Excellent \\
\hline $\begin{array}{l}\text { Facilitated student case } \\
\text { presentations }\end{array}$ & $\begin{array}{l}\text { Not equitable } \\
\text { Completion of } 12 \text { CBD's post- } \\
\text { session }\end{array}$ & $\begin{array}{l}\text { Variable; Less } \\
\text { desirable nearer to } \\
\text { exam time }\end{array}$ \\
\hline Cerebral palsy teaching at & Not equitable & Very good \\
\hline Bobath centre & $\begin{array}{l}\text { Teaching discontinued due to } \\
\text { centre moving }\end{array}$ & \\
\hline Community clinics & $\begin{array}{l}\text { Influenced by patient attendance } \\
\text { and patient's progress on care } \\
\text { pathway }\end{array}$ & $\begin{array}{l}\text { Variable learning } \\
\text { experience }\end{array}$ \\
\hline \multicolumn{3}{|l|}{ Currrent: } \\
\hline Interactive case-based learning & $\begin{array}{l}\text { Covered limited number of core- } \\
\text { curriculum topics }\end{array}$ & Good \\
\hline Introductory lectures & Poor student attendance & Unknown \\
\hline
\end{tabular}

The challenges above and changes to the new 2019-2020 MBBS programme, has resulted in significantly less time allocated for formal community paediatric teaching and more frequent sessions expected to be delivered (every 3 weeks, previously every 6 weeks) which requires more teaching staff, with already limited capacity.

Methods We developed a simulation programme consisting of 3 scenarios, covering 6 core curriculum topics using low-fidelity and low cost simulation equipment, aiming to provide :

- An equitable, standardised and sustainable teaching programme

- Focused curriculum mapping covering core topics in community paediatrics

- Prioritising the learners' needs

- Regular exposure to experiential learning opportunities

Assessment Medical student and teacher feedback was obtained to drive improvements (e.g. pre-reading material and workbook with dedicated time to complete prior to the session) and to describe learner experience.

To date, 23 students have participated and feedback has been overwhelmingly positive especially relating to small group facilitation $(10 / 23 ; 43 \%)$, practical $(7 / 23 ; 30 \%)$ and interactive $(5 / 23 ; 22 \%)$ style.

Students also benefited from enhancing their generic and transferable skills (e.g. focused history taking, structured general examination, SBAR handover).

Conclusion Simulation can be an effective, equitable and costeffective way to deliver community paediatric teaching to 5 th year medical students. To ensure sustainability, sufficient numbers of facilitators for each session is required.

\section{G208(P) A NEW REGIONAL LEVEL 3 TEACHING PROGRAMME: REVIEWING SUCCESS ONE YEAR ON}

I Morgan, A Christie, A McKie. Royal Hospital for Children, NHS Greater Glasgow and Clyde, Glasgow, UK

10.1136/archdischild-2020-rcpch.176

Introduction The RCPCH Trainee Charter sets standards for postgraduate medical education, based on GMC guidance. 
Doctors in training should have protected time to attend high quality, relevant education and this should be audited. Before 2018, Regional Level 3 Paediatric teaching was delivered on a mainly ad hoc basis, with deficiencies reported in addressing curriculum competencies by recent GMC and NES (NHS Education for Scotland) surveys.

Aim To assess the success of a new regional Level 3 teaching programme in providing accessible, relevant teaching to trainees.

Methods A new committee of senior trainee volunteers, with a Consultant Supervisor, was set up. Themes from the $\mathrm{RCPCH}$ Progress Curriculum were identified, to be delivered monthly on a rolling annual basis. Focus groups of committee members organised and led each session. Attendance was taken, and attendance certificates were awarded after feedback form submission. After one year of implementation, trainees completed an online survey assessing their opinion of the new teaching programme. Members of the teaching committee filled in an additional survey relating to their role.

Results The average number of trainees attending per session was 19. Overall, attendance was 51\% ST6, 29\% ST7 and $20 \%$ ST8. Percentage of trainees present per session from total trainees at site (over 6 sites) ranged from 23\% to $62 \%$ (Median 45\%). 83\% provided feedback. Each session score was above 4 (on a scale of 1-5) with a range of 4.06 to 4.92. $95 \%$ of trainees found the sessions accessible, and $76 \%$ enjoyed the face-to-face nature. $90 \%$ agreed or strongly agreed that the teaching was relevant to their stage of training.

$56 \%$ of committee members were ST8, 33\% ST7, and $11 \%$ ST6. $100 \%$ reported that they had a clear idea of session focus and $86 \%$ that it was easy to record attendance and feedback. Committee members felt well supported in $100 \%$ of cases. Formal feedback was provided to speakers in $100 \%$ of cases.

Conclusions The programme is well received by trainees, who find sessions accessible and useful. Volunteers find organising straightforward and well supported. Attendance, however, varies by site and grade. Our next steps are to evaluate future NES and GMC surveys, and facilitate improved attendance.

\section{G209(P) WHAT IMPACTS PAEDIATRIC TRAINEES' PERCEPTIONS OF BLOGS?}

GF Appleby. University Hospital Lewisham, London, UK

\subsection{6/archdischild-2020-rcpch. 177}

Aims To explore what affects paediatric trainees' views about blogs as learning tools.

Methods Trainees volunteered to complete an online survey and/or participate in a 1:1 interview, all responses were pseudo-anonymised. A modified constructive grounded theory approach was used to analyse the results.

Results Twenty-three trainees participated, table 1:

Blog experiences can be categorized as being determined by: self, others and organisational factors.

Self: Trainees' blog use was found to be on a spectrum ranging between: non-user, casual user, active follower and sharer. No participants identified as blog creators, which could be an additional subgroup. Trainees who reported being non-

\begin{tabular}{lllll}
\multicolumn{4}{l}{ Abstract $\mathbf{G 2 0 9 ( P )}$ Table $\mathbf{1}$} & \\
\hline $\begin{array}{l}\text { Trainee } \\
\text { Grade }\end{array}$ & Survey & Interview & Both & Total \\
\hline ST1-3 & 8 & 1 & & \\
ST4-5 & 5 & 2 & 1 & 8 \\
ST6-8 & 4 & 1 & 1 & 6 \\
Total & 17 & 4 & 2 & 23 \\
\hline
\end{tabular}

users were sceptical about the accuracy of the writing on blogs as the information may be unchecked especially if unreferenced.' ST1-3. Whereas, for others the gains from readership outweighed doubts, although tension between trusting blogs fully was pervasive throughout all interviews. Benefits relating to clinical practice included: improved communication skills, affirming practice and knowledge acquisition. Other advantages included: perspective and connectivity.

Others' Influence: Blog access was influenced by direct recommendations, which were mostly made by registrars and/or consultants. These nudges also occurred from institutions: 'by having the stamp of approval [Organisation] [this] was something ... of an endorsement' Blake. A blog writer's reputation could also influence trainees in deciding whether to engage; for example, when a blog is written 'by a Dr whom I know is one of the leading people... I feel quite safe....that it's pretty reputable' Taylor.

Organisational Factors: This can relate to stylistic features such as ease of access which was the most important influence on user experience. Equally support at an organisational level also 'gives it that little bit of extra sway... [for trainees] to start engaging with it' Blake.

Conclusions This project illustrates there are a myriad of interlinking factors that influence trainees' perceptions and experience of blogs. An understanding of this complexity may aid future development and design of blogs and online educational content.

\section{Association of paediatric emergency medicine}

\section{G210 ADDRESSING PAEDIATRIC OBESITY IN THE EMERGENCY DEPARTMENT: CLINICIANS CURRENT ATTITUDES AND THE BARRIERS THEY FACE - A PERUKI STUDY}

${ }^{1,2} \mathrm{R}$ Tricks, ${ }^{2} \mathrm{C}$ Gough, ${ }^{3} \mathrm{E}$ Walton. ${ }^{1}$ Faculty of Medicine and Health, University of Leeds, Leeds, UK; ${ }^{2}$ Emergency Department, Nottingham University Hospitals, Nottingham, UKi ${ }^{3}$ PERUKI, UK

\subsection{6/archdischild-2020-rcpch.178}

Background Rates of childhood obesity are increasing. Traditional strategies including school nurses are overwhelmed. Strategies to discuss weight and impact on health, including 'Make every contact count', are challenging in the Emergency Department (ED), in part due to rising attendances and an increasingly strained service. Other 'Quick-win' interventions (e.g. smoking cessation) have been attempted in ED. Ascertaining the current attitudes of clinicians towards addressing obesity in the ED and the barriers they face can support development of long term solutions to obesity management in children. 